\title{
Inspection of Supersonic Flows in a CD Nozzle using Experimental Method
}

\author{
Muhammed Hanafi Azami, Mohammed Faheem, Abdul Aabid, Imran Mokashi, S. A. Khan
}

\begin{abstract}
In high speed flows nozzles are used to change pressure energy to kinetic energy which in turn is used to produce thrust. In a converging-diverging nozzle, flow is augmented from subsonic to sonic velocity at the throat and further expanded to supersonic velocities at the exit. In this paper, an experimental study is performed to evaluate the supersonic flow in a CD nozzle with a suddenly expanded duct. At the base of the nozzle, the base pressure is controlled by employing tiny jets of $1 \mathrm{~mm}$ diameter with a circular crosssection having exit Mach number of as unity are arranged at ninety degrees at a PCD of $13 \mathrm{~mm}$ and $6.5 \mathrm{~mm}$ from the central jet axis. Obtained wall pressure distribution is shown for Mach number 2.8, and Axi-symmetric round brass duct was used to join micro-jets, an area ratio of that duct is 3.24. Tests were conducted for $L / D$ from 10 to 1 , and the level of expansion for tests considered for wall pressure data acquisition was from 3, 5, 7, 9 and 11. The results indicate that the flow field was not aggravated due to the deployment of the control.
\end{abstract}

Keywords-CD Nozzle, Microjet; Wall Pressure; and Mach number.

\section{INTRODUCTION}

The study of suddenly expanded flow has many important applications in the automobile industry, high-speed jets, rockets, missiles and in external flows over projectiles and shells. With the requirement to obtain missiles and rockets to encounter the upcoming financial and technical requisites, the behavior of the nozzle flow must be observed into additional. With the future researches on nozzles for propulsion arrangements, the implementation and consequences are improving together with the saving of cost, which is the most comforting matter. In these nozzles, as the flow suddenly expands, suction zones are created at the base of the duct. The pressure is usually a smaller amount in the base region in the evaluation of atmospheric pressure. It is thus essential to plan the extended duct and select the best design to produce better usage of CD nozzle.

Khan et al., [1]-[7] experimentally investigated the effectiveness of the microjets in the CD nozzle with the suddenly expanded duct. In all studies of experimental, the authors' used the 4-microjets of one-millimeter circular steel pipe were located at ninety-degree interval along the base at $6.5 \mathrm{~mm}$ from the geometrical axis of the main jet in the base

Revised Manuscript Received on July 10, 2019.

Muhammed Hanafi Azami, Dept. of Mechanical Engineering,

Faculty of Engineering, International Islamic University, Kuala Lumpur, Malaysia, (hanafiazami@iium.edu.my)

Mohammed Faheem, Dept. of Mechanical Engineering Faculty of Engineering, International Islamic University, Kuala Lumpur, Malaysia. Abdul Aabid, Dept. of Mechanical Engineering, Faculty of Imran Mokashi, Dept. of Mechanical Engineering Faculty of Engineering, International Islamic University, Kuala Lumpur, Malaysia.

S. A. Khan, Dept. of Mechanical Engineering, Faculty of Engineering, International Islamic University, Kuala Lumpur, Malaysia,
Engineering, International Islamic University, Kuala Lumpur, Malaysia.

area was employed as controls mechanism. The wall pressure distribution was examined without and with microjets controller. The experiments were conducted in the open jet wind tunnel facility, and from the results, it was apparent that for an obtained for inertia level and the level of expansion one can find the duct length and relief to the flow which will result in a most tremendous or lowest value of the base pressure. The results show that for a given Mach number and nozzle pressure ratio (NPR) one can identify the enlargement of length-to-diameter (L/D) ratio which will result in maximum rise/fall of base pressure. Baig et al., [8], presented the measured data from the wind tunnel study to control the base pressure in an enlarged axi-symmetric duct. Dynamic control in the method of microjets was hired to control the base pressure at the blunt base of the body. Microjet is injected at four different locations at the base, symmetric to the nozzle axis can be used as an active control. The jet Mach numbers at the entry to the enlarged duct considered were 1.87, 2.2 and 2.58. The cross-sectional area of the current work was 2.56 . The L/D ratio of the enlarged duct diverse from 10 to 1 . Nozzles successful in developing above jet inertia level were used with NPR of 3, 5, 7, 9, and 11 .

Khan et al. [9] experimentally investigated the information on internal supersonic flows in a CD with suddenly expanded axi-symmetric duct. The authors' found that the microjets controller does not adversely influence the results of wall pressure. They tested Mach numbers for 1.25, 1.3, 1.48, 1.6, 1.8, 2.0, 2.5 and 3.0 and L/D considered from 10 to 1 . The nozzles calibrated at the above jet Mach were tested for NPR 3, 5, 7, 9, and 11. Similarly, the effectiveness of the flow controllers to govern the pressure at the base in a suddenly expanded duct has been examined. Microjets four in some one-mm diameters are positioned at the interval of 90-degrees at PCD $13 \mathrm{~mm}$.

Quadros et al., [11] used the design of experiments method (DOE) to optimize the results. The DOE method used in manufacturing applications [14]. This method is used by the authors to examine the base pressure with and without tiny jets controller. They used different DOE technique to optimize and analyze the results. The cases they used on their studies depend on Taguchi design and full experimental design. In order to optimize the results, they used statistical analysis, surface response methodology, and analysis of variance (ANOVA) experimental methods. The authors also proved the coefficient of the factors that can actively control the pressure at the base region of the CD nozzle using microjet control.

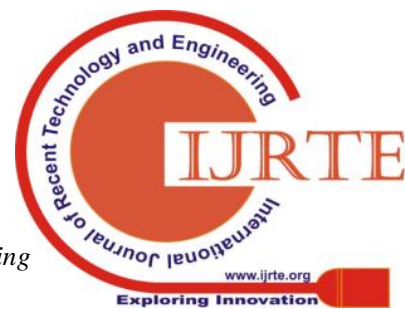


Moreover, they also improved the internal flow of the wall pressure on suddenly expanded CD nozzle with the best-fitted parameters.[10][12][13]

The computational fluid dynamics method using ANSYS FLUENT [15][16] commercial code some investigations have been found from last decades few of them are specified here. An ANSYS simulation was done to find out the effect of microjets to regulate the pressure in the wake of the twodimensional convergent-divergent nozzle. The CD nozzle was modeled, and the flow was numerically simulated using turbulence K- $\varepsilon$ models customary wall function turbulence model was independently checked from the model with Ansys CFD code [18][19]. CFD method is also used to simulate the supersonic flow over the wedge [21]. From the above literature it has been observed there is no work stated with active control effect of wall pressure distribution for Mach number 2.8 and area ratio 3.24. Therefore, in the present work, an effort is made to investigate the wall pressure distribution with active control in the form of a microjet controller under a favorable pressure gradient.[20]

\section{EXPERIMENTAL STUDY}

Figure 1 shows the essential features of sudden expansion flow filed showing the reattachment point, expansion waves, and recirculation zone. The same concept is used to perform micro jets at the base as shown in Figure 2. Figure 2 demonstrates the setup used for the experiment in the present study which is also discussed in [17]. The investigation was performed with a full-scale experimental model consisting of pipelines, pressure transducers, and the experimental model, it is first allowed to go through regulating valves. The experimental model is a nozzle with an augmented duct. The flow leaving the duct is subjected to ambient air. Figure-1 depicts the experimental setup with the nozzle and duct where the flow expands. In the outlet boundary of the nozzle, eight holes of $1 \mathrm{~mm}$ diameter each are drafted. Control of base pressure is achieved by passing the pressurized air through the control holes [22]. Wall pressure tapes are also present to scale the nature of the flow field, the influence of the control on the magnitude of the wall pressure in the duct. The pressure range is 0-300 psi of the transducer employed, and it has 16 channels. The sampling rate of the pressure transducer is 250 samples per second, and then the reading is displayed on the monitor and recorded. The wall pressure was recorded using mercury manometer.

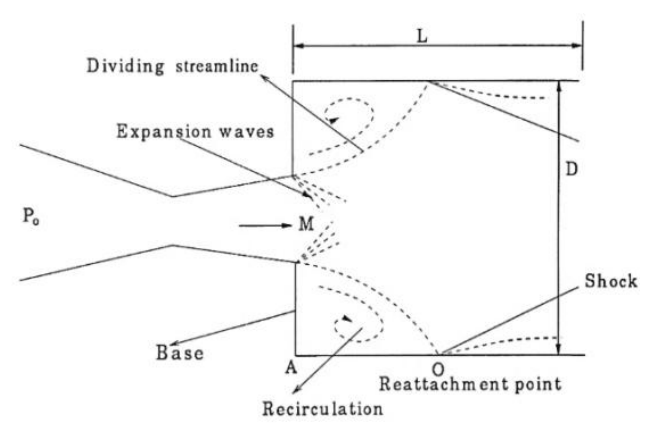

Figure 1: Sudden Expansion Flow Field. the experimental investigation with the application of four settling chamber. In order to expand the gas through the

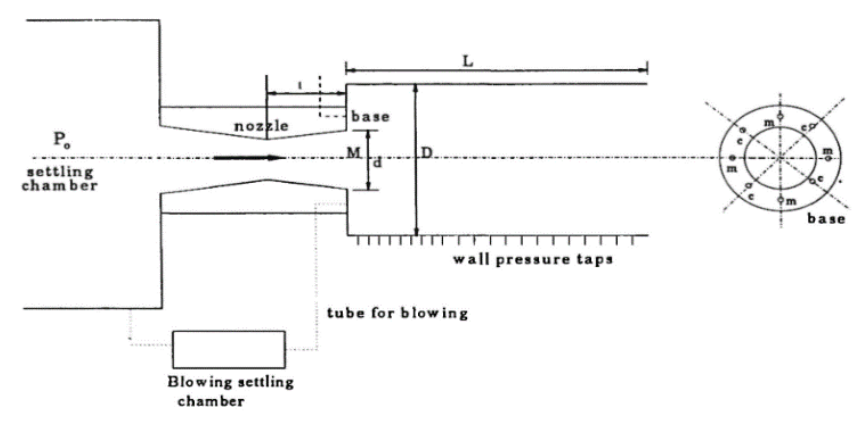

Figure 2: Experimental Setup.

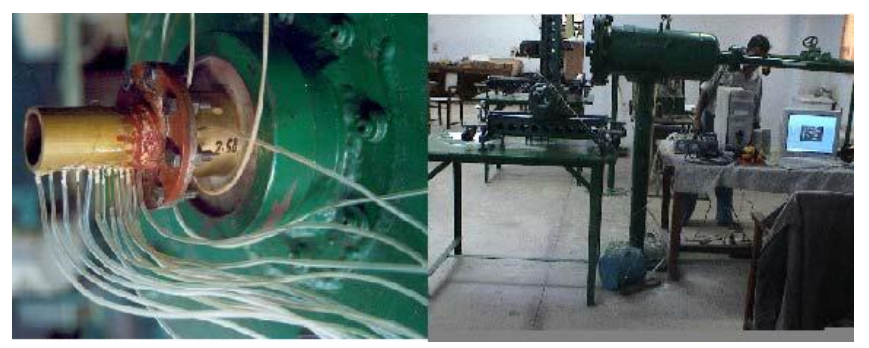

Figure 3 A View of Suddenly Expanded Duct with Pressure Tapings and setup location [13]

\section{RESULTS AND DISCUSSION}

Figures 4 present the wall pressure distribution in the enlarged duct for area ratio 3.24, for some selected combination of Inertia levels. For this area ratio of 3.24 is the case of slightly increased relief for the expanding flow.

Figs. 4 presents the results for Mach 2.8. From the results, it is seen that the results at Mach 2.8 are behaving differently since the jets remained over expanded throughout for the NPR's tested. Due to the very high level of overexpansion, the starting values of wall pressure are very close to the atmospheric pressure for all the L/Ds for Lower NPR's namely 3 and 5. Due to the over expanded jets, the non-dimensional wall pressure ratios remained less than 1 whereas, this ratio was 1.5 at the lower Mach numbers. Under these circumstances when the jets are exiting from the nozzle into the enlarged duct, the wall pressure recovery takes place smoothly without variations. As the jets are already over-expanded and they attain higher wall pressure values at the exit of the nozzle, hence the peak values are 5 $\%$ above the ambient pressure as the significant wall pressure recovery has taken at the initial stage itself Therefore, further jump in the wall pressure is not observed. As discussed earlier at Mach 2.1, the similar results are seen at Mach 2.8. At $\mathrm{L} / \mathrm{D}=10$ the control results in an increase of the wall pressure for NPR's 11, for the rest of the NPR the control effectiveness is marginal. The trend which was seen at NPR 3 at lower Mach numbers this trend continues at Mach 2.8 for NPR from 3 to 9 (Figs. 4(a)).

Fig. 4 (b) presents the identical wall pressure results for $\mathrm{L} / \mathrm{D}=8$ as was observed in the previous figure with the exception that the wall pressure fluctuation has reduced considerably and remained with $20 \%$ of the duct length. Figs. 4((c) to (d)) represent the wall pressure results for L/D $=6$ and 5 with the exception that due reduction in the L/D 
ratio there are no oscillations in the wall pressure. Due to the influence of back pressure and the peak pressure values are less than that those were for higher L/D ratios namely $(\mathrm{L} / \mathrm{D}=10$ and 8$)$ especially in respect of $\mathrm{L} / \mathrm{D}=5$. Also, the flow field has smoothened in the duct, and wall pressure values with and without microjets are identical. This trend continues until $\mathrm{L} / \mathrm{D}=4$ (Figs. $4((\mathrm{e})$, then later for lower $\mathrm{L} / \mathrm{Ds}$ like $\mathrm{L} / \mathrm{D}=3,2$, and 1 , it is evident that this length is not enough for the flow to remain attached with the duct wall and it is suggested that these values may be ignored.

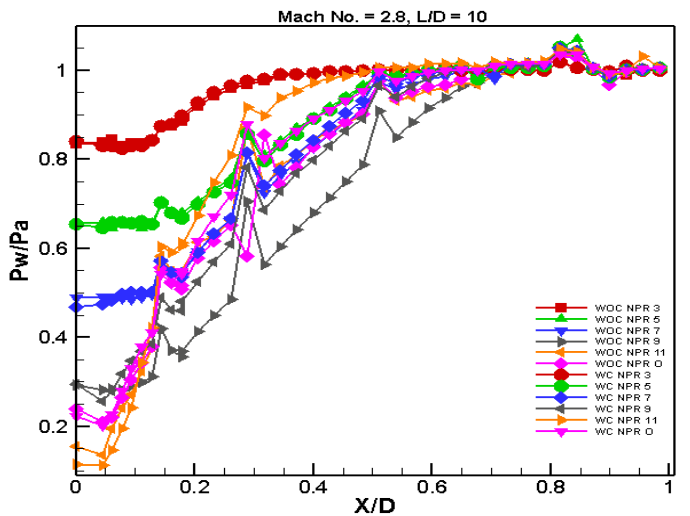

(a)

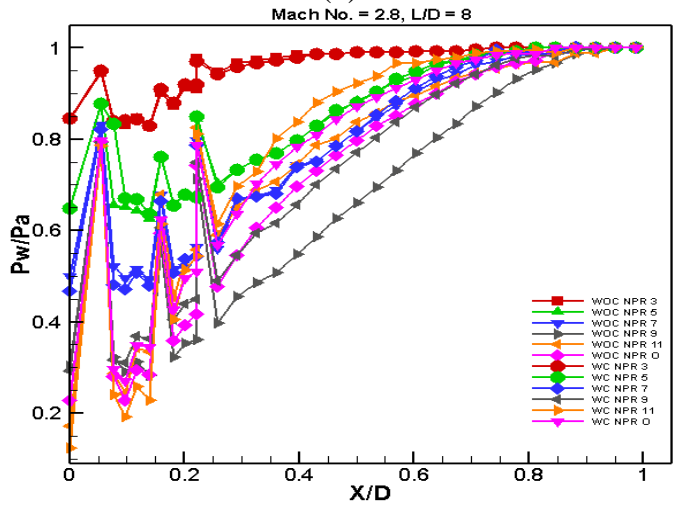

(b)

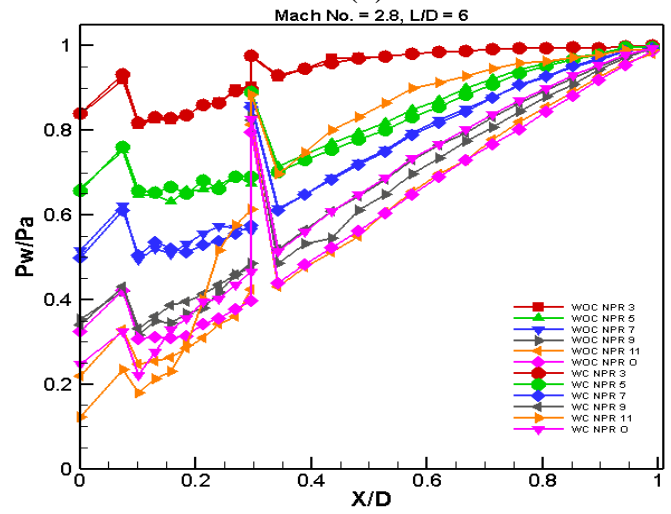

(c)

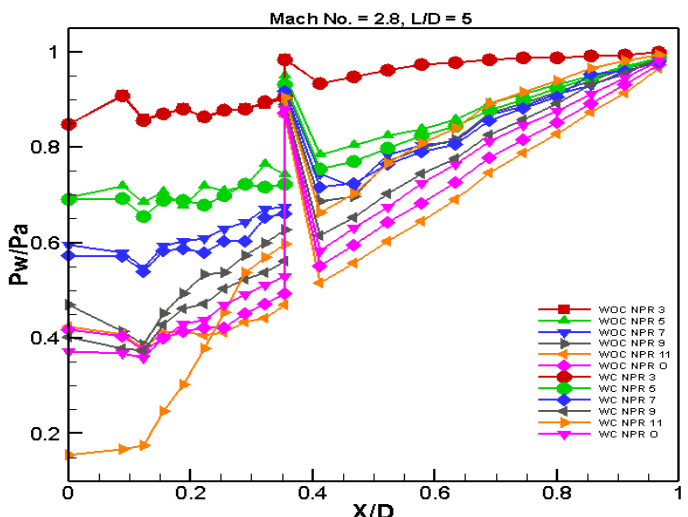

(d)

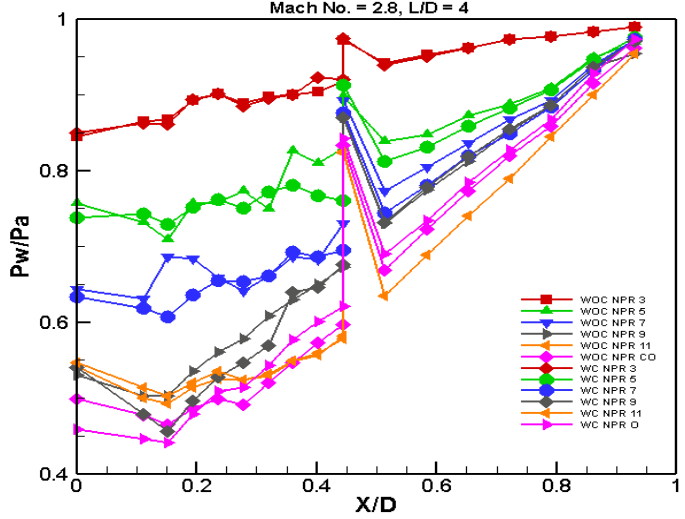

(e)

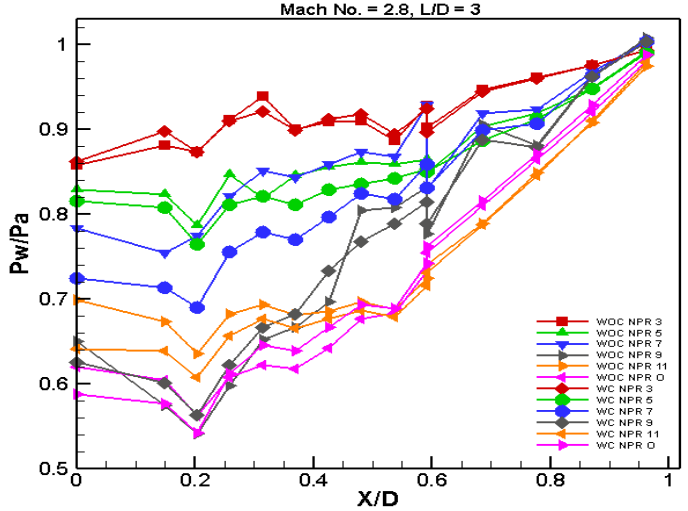

(f)

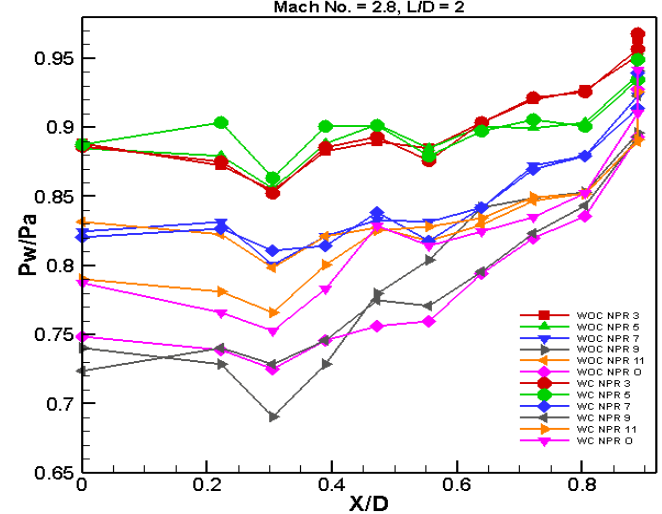

(g)

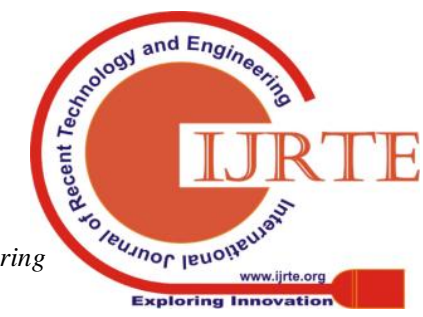




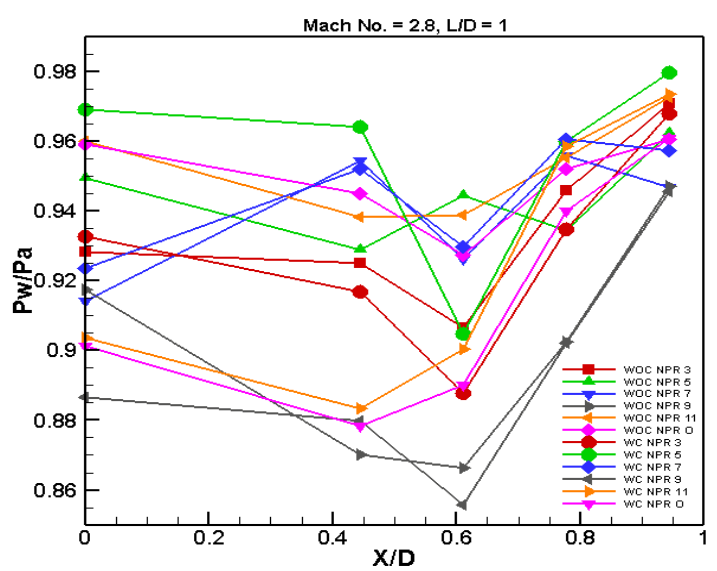

(h)

Figure 4. Wall Pressure Vs. X/D

\section{CONCLUSION}

Experimental analysis of wall pressure changes in the duct for suddenly expanded flows is studied in this work. CD nozzle is used for the flow expansion, and the duct is having an area ratio of 3.24 and L/D from 10 to 1 at Mach numbers 2.8 . From the analysis the following conclusions are drawn:

- In this study, the control of the base pressure in the recirculation zone at the base corner and the flow field in the duct by microjets is demonstrated.

- The microjets are found to be effective at this Mach number and area ratio 3.24.

- The use microjets result in a decrement of suction at the base and decrease of associated drag at these combinations of parameters, resulting in an 83 percent increase in base pressure.

- The active control does not adversely influence the duct wall pressure distribution

\section{ACKNOWLEDGMENT}

The corresponding author would like to thank and acknowledge International Islamic University Malaysia for the FRGS Grant (FRGS19-063-0671) for this research project.

\section{REFERENCES}

1. S. A. Khan and E. Rathakrishnan, "Active Control of Suddenly Expanded Flows from Overexpanded Nozzles," International Journal of Turbo and Jet Engines, vol. 19, pp. 119-126, 2002.

2. S. A. Khan and E. Rathakrishnan, "Control of Suddenly Expanded Flow with Micro-Jets," International Journal of Turbo and Jet Engines, vol. 20, pp. 63-82, 2003.

3. S. A. Khan and E. Rathakrishnan, "Active Control of Suddenly Expanded Flows from Underexpanded Nozzles," International Journal of Turbo and Jet Engines, vol. 21, pp. 233-254, 2004.

4. S. A. Khan and E. Rathakrishnan, "Control of Suddenly Expanded Flows from Correctly Expanded Nozzles," International Journal of Turbo and Jet Engines, vol. 21, pp. 255-278, 2004.

5. S. A. Khan and E. Rathakrishnan, "Active Control of Suddenly Expanded Flows from Underexpanded Nozzles Part II," International Journal of Turbo and Jet Engines, vol. 22, pp. 163-183, 2005.

6. S. A. Khan and E. Rathakrishnan, "Control of suddenly expanded flow," Aircraft Engineering and Aerospace
Technology: An International Journal, vol. 78, no. 4, pp. 293309, 2006.

7. S. A. Khan and E. Rathakrishnan, "Nozzle Expansion Level Effect on Suddenly Expanded Flow Sher," International Journal of Turbo and Jet Engines, vol. 23, pp. 233-257, 2006.

8. S. A. Khan, M. Asadullah, F. Ahmed G M, A. Jalaluddin, and M. A. A. Baig, "Flow Control with Aerospike behind Bluff Body," Int. J. Mech. Prod. Eng. Res. Dev., vol. 8, no. 3, pp. 1001-1008, 2018.

9. S. A. Khan, Z. I. Chaudhary, and V. B. Shinde, "Base pressure control by supersonic microjets in a suddenly expanded nozzle," Int. J. Mech. Mechatronics Eng., vol. 18, no. 4, pp. 101-112, 2018.

10. S. M. Umair, A. Alrobaian, S. A. Khan, G. Kashinath, and P. Rajesh, "Numerical Investigation of Critical Range for the Occurrence of Secondary Peaks in the Nusselt Distribution Curve Akademia Baru," CFD Lett. 10, vol. 2, no. 2, pp. 1-17, 2018.

11. J. D. Quadros, S. A. Khan, and A. A. J, "Investigation of the effect of process parameters on suddenly Expanded flows through an axi-symmetric nozzle for different Mach Numbers using Design of Experiments," in IOP conf. Series: Materials Science and Engineering, 2017, p. 8.

12. I. B. Hamizi and S. A. Khan, "Aerodynamics Investigation of Delta Wing at Low Reynold's Number," vol. 2, no. 2, pp. 32-41, 2019.

13. S. A. Khan, A. Aabid, and C. A. Saleel, "Influence of Micro Jets on the Flow Development in the Enlarged Duct at Supersonic Mach number," no. 01, 2019.

14. R. F. A. E. Crew, Edinburgh D. Ward Cutler, Statistical Methods for Research Workers. London, 1934.

15. ANSYS Inc, "ANSYS FLUENT 18.0: Theory Guidance," Canonsburg PA, 2017.

16. S. A. Khan, A. Aabid, and A. Saleel . C, "CFD Simulation with Analytical and Theoretical Validation of Different Flow Parameters for the Wedge at Supersonic Mach Number," no. $01,2019$.

17. K. A. Pathan, P. S. Dabeer, and S. A. Khan, "An investigation to control base pressure in suddenly expanded flows," Int. Rev. Aerosp. Eng., vol. 11, no. 4, pp. 162-169, 2018.

18. A. G. M. Fharukh, A. A. Alrobaian, A. Aabid, and S. A. Khan, "Numerical Analysis of Convergent-Divergent Nozzle Using Finite Element Method," International Journal of Mechanical and Production Engineering Research and Development, vol. 8, no. 6, pp. 373-382, 2018.

19. A. Aabid, A. Khan, N. M. Mazlan, M. A. Ismail, M. N. Akhtar, and S. A. Khan, "Numerical Simulation of Suddenly Expanded Flow at Mach 2.2," International Journal of Engineering and Advanced Technology, vol. 8, no. 3, pp. 457-462, 2019.

20. S. A. Khan, A. Aabid, and C. A. Saleel, "Influence of Micro Jets on the Flow Development in the Enlarged Duct at Supersonic Mach number," International Journal of Mechanical and Mechatronics Engineering, vol. 19, no. 01, pp. 70-82, 2019.

21. S. A. Khan, A. Aabid, and C. A. Saleel, "CFD Simulation with Analytical and Theoretical Validation of Different Flow Parameters for the Wedge at Supersonic Mach Number," International Journal of Mechanical and Mechatronics Engineering, no. 01, 2019.

22. S. A. Khan, A. A. Alrobaian, and M. Asadullah, "Threaded Spikes for Bluff Body Base Flow Control," J. Adv. Res. Fluid Mech. Therm. Sci., vol. 53, no. 2, pp. 194-203, 2019.

Published By:

Blue Eyes Intelligence Engineering \& Sciences Publication 